\title{
4
}

\section{Consuming Space Slowly: Reflections on Authenticity, Place and the Self}

\author{
Nick Osbaldiston
}

\section{Introduction}

Slow living may not necessarily be limited to particular places, but there are, nonetheless, certain kinds of spaces that best facilitate slow living and the value of these arises from a consideration of their contexts in the deterritorialised global culture in which we live (Parkins and Craig 2006, p. 63).

Throughout the academic debates that engage in slow culture, there is a recurring theme of time. Indeed, throughout this volume, time is a prominent feature of analysis not just in relation to the clock or calendar. There is a need to consider time further in relation to all modes of temporality as well, including aging, natural rhythms and other 'times' which contribute to slow movements (cf. Adam 1990, 1995). It might be that in the future, theoretical engagement with slowness could embrace a 'timescape' project which encapsulates a range of temporalities that coalesce to create the potentiality of slow living (Adam 1998). For instance, nostalgia or at least a collective version of it (Davis 1979) could be seen as an important motivator to return back to the 'good ol' days before society became hyper-consumerist.

In this chapter, however, I want to posit that important in the development of slow culture is the problem of spatial relations. Certainly the subject of place/space has been high on the agenda of those seeking to understand amenity-led migration or Lifestyle Migration for some time (see Benson and O'Reilly 2009; Benson 2011; Moss 2006; Ragusa 2010, this volume; Osbaldiston 2011, 2012). However, none of these assessments of this migratory phenomenon seeks to link the movement back to slow narratives (the exception being Osbaldiston 2012). 
Furthermore, the negotiation of space within the everyday has been limited in relation to slowness. Kate Soper's (2007) 'Alternative Hedonism' discourse is an exception in that it provides some important insight in relation to how people engage with space differently, which can have political implications long term, specifically under the banner of sustainability.

Parkins and Craig (2006) have also entertained the notion of place/space in their work on slow living. Specifically they consider two areas where spatial relations encourage slowness. One area is in the home where it is 'possible to mobilize a positive potential in domestic space in the conceptualizing of the spatial contexts of slow living' (Parkins and Craig 2006, p. 65). They argue that

[t]he home is an important site in slow living because it can represent a demarcated sphere of existence that can facilitate a particular quality of time. That is, the home can represent a relatively fixed site in the flux of everyday experience and in this sense it is a space that can enable the kind of care and attentiveness that we have posited as central to slow living.

(Parkins and Craig 2006, p. 65)

Certainly the home plays an important role in the representation of the self but also in the development of meaning in an individual's life (see Woodward 2007). The arrangement of the home and the markers of identity found in material objects are potentially important sites for analysis in the binary division between work and private life. What activities occur within the confines of the home are also of great interest. Quality time with children and partners acts to counter the influence of the 'pressures of speed' found in the everyday (Parkins and Craig 2006, p. 64; for more on 'quality time', see Hochschild (1997)). From this perspective, the home becomes the 'haven in the heartless world' (Lasch 1979), a place where the family is a refuge and 'where the wounds of life find their consolation' (Davy 1925, cited in Lamanna 2004, p. 15).

However, the relatively mundane setting in the home is not the only space where slowness can be initiated. Parkins and Craig (2006) finalise their analyses of space and slow living by exploring Cittaslow or Slow Cities. The movement, which follows closely after the fundamental tenets of Slow Food, seeks to reconnect townships back to a more authentic identity. Important in this, as Parkins and Craig (2006, p. 83) propose, is not just an 'aesthetic of rural', though vital, but a shaping of 
the townships' aesthetic towards a rich and meaningful sense of place. Subsequently, the vices of the metropolis are actively avoided through planning mechanisms and policies that seek to limit vehicular traffic and instantaneous consumption (e.g. of fast foods) while promoting alternative activities, such as food markets (which tie back to a collective identity through food consumption of local traditional cuisine and local produce) and community events. While the notion of an authentic community derived through nostalgia for times forgotten is quite obviously socially constructed, Parkins and Craig (2006) remind us that this can have a very real impact on individual identity. Thus, while notions of rurality important to the movement can be criticised for being dependent upon a 'middle-class' version of what is 'real' (see Murdoch and Day 1998; Pahl 2005), Parkins and Craig (2006, p. 85) are quick to remind us that the Cittaslow movement remains a powerful narrative against the tide of fast-paced globalisation that often dislocates and displaces local traditions and communities, having a detrimental impact therefore on the individual.

Our point here is that the mindful consciousness that we position as central to slow living generates an awareness of the specificity of place, and more particularly a material relationship to the land, as well as an attentiveness to those who coexist in the same territory and who collectively give their territory identity and value. This is not based upon a bourgeois, romantic valorization of either rural life or small, sophisticated towns in exotic locales, but is rather based upon a belief that in the contexts of our fast, deterritorialised, modern lives, we need to retain an ethical and political disposition that is grounded in awareness of our fundamental relationship to the specificity of place, the land, its produce and each other.

(Parkins and Craig 2006, p. 85, italics added)

Others through ethnography tell a story of Cittaslow that is engaging and important. Pink (2007), for instance, demonstrates how the towns embrace different sensations compared with the city, while Miele (2008, p. 148) empirically shows how Cittaslow places use 'Slow Food technologies for performing boundaries between slow and fast'. In each instance, the binary between city and the homogenous influence of globalisation and the 'slow town' is demonstrated as having a heavy influence on the everyday experience of those within the townships.

By concentrating on Cittaslow and the home, however, Parkins and Craig (2006) limit their discussion of place in the context of slowness. 
A host of social behaviours embedded in the 'slow' philosophy are seen not just through movements such as lifestyle or amenity migration but also within everyday life (Soper 2007). Once this debate is opened up beyond the political as well, the expansive influence of the slow narrative on spatial practices becomes apparent. Further, by doing so the darker side to slow living also begins to emerge. Surprisingly, Parkins and Craig (2006) neglect any reading of slow culture through critical theorists like Bourdieu. Such notions are central tenets to theses from Karen O'Reilly and Michaela Benson (see below). Furthermore, as Simmel (1997[1895], p. 220) once fatalistically declared, 'the power of capitalism extends itself to ideas as well'.

This chapter, however, is not fatalistic. It does not argue that all slow movements are necessarily doomed to neither fall victim to hyperconsumerist tendencies nor lose their inherent 'alternative hedonist' qualities (Soper 2007). Rather, it seeks to engage with differing spatial practices under the guise of slowness and thus present a reading of place that is different from those of Parkins and Craig (2006). While these two authors advance a case for slowness and space/place that is coherent and highly engaging, they are unnecessarily dependent on analysing organised social movements, like Cittaslow, in their works. In this chapter, I wish to explore the cultural conditions that encourage a range of slow activities through both the everyday and the more exotic ritualistic escapes. In both instances, the role of the city is predominant. As Parkins and Craig (2006) note in particular, the metropolis creates the spatial possibilities for the embracing of slow lifestyles. While they do not explicitly characterise the city as profane or degrading on the self, there is a hint that they consider it as the primary seat for a homogeneity which is developed through globalisation. Yet, the city also encourages a cosmopolitan self which opens up the individual to possibilities beyond the urban environment. So while the metropolis is dotted with 'homogenized "non-places" ', we must also be fully aware of the potential that global city culture has to produce a sense of oneness with the world (Parkins and Craig 2006, p. 71; see also Kendall, Skrbis and Woodward 2008; Beck 1992, 2006).

In what follows, however, the city is described as a site for highly mundane activities but also one which can, in Durkheimian language, suffer a decline in status towards the 'profane' (Smith 1999; Osbaldiston 2012). While some engage with alternate activities in the city with a quasi-adventure type of attitude (Simmel 1997[1910]), others find themselves in a push-pull situation where the lifestyles of the city and the promises of the rural/coastal life encourage a ritualistic escape into 
'sacred places' (Smith 1999). Lifestyle or Amenity Migration (Benson and O'Reilly 2009; Benson 2011, forthcoming; Moss 2006; Osbaldiston 2011; Ragusa 2010; Hoey 2010) is one such manifestation of this dilemma. It has become a worldwide phenomenon and subsequently deserves some consideration in the analysis of the slow (see Parkins and Craig 2006, p. 67 for a brief reading of this phenomenon). However, not all 'escapes' from the city are permanent. Overseas tourism, for instance, bears witness to another form of escapism - the temporary journey from the mundane to the extraordinary. Under the guise of the slow paradigm, 'slow tourism' has developed as an alternative mode of touring other places (Lumsdon and McGrath 2011; Dickinson, Lumsdon and Robbins 2010). At the foundations of slow tourism, the slow tourist is the antithesis of the postmodern subject who treats the tourist moment as a fleeting experience or game rather than as an opportunity for self-fulfilment and authenticity (Rojek 1993; Urry 2002, 2011; Craik 1997). Slowness, as Parkins and Craig (2006) describe, however, seeks for moments of meaning, contemplation and care. While there are inherent political narratives embedded in slow travel (such as environmental concerns), the underlying cultural narrative is one which promotes a quest for the authentic, or potentially seeks out the sacred for the enhancement of the self (Cohen 1979; Smith 1999; Shields 1992).

\section{A mundane city?}

Before examining these engagements with space in detail, though, it is first important that we discuss the role of the city in modern life. Parkins and Craig (2006), as mentioned earlier, view the city through the paradigm of cosmopolitanism; or rather the potential for cosmopolitan identity to be formed individually. Yet alongside this is a homogenisation of place and the proliferation of spaces that are meaningless or 'placeless' (Relph 1976). In other words, the indistinguishable features of a metropolitan shopping mall, including the countless fast-food, retail and other outlets, create a landscape that is bland. The impact of their increased presence in the city strips away a sense of connectivity with place for individual identities. Such ideas have permeated through sociology and geography since modernisation. As Simmel (1997[1903]) proposes in his famous 'Metropolis and mental life' essay, the city has long been regarded as overwhelming and inhibiting. The design of the cities, for the classical sociologist, is such that it encourages a flat and dull attitude towards things (objects) and inculcates distrust and disdain 
towards other people deemed strangers. The latter point is evident in the disposition which 'small-town people' have towards urbanites who are considered 'cold and heartless' (Simmel 1997[1903], p. 179). These ideas permeate discourses and narratives of the country/city dialectic in Lifestyle Migration, or Seachange as it is referred to in Australia (Osbaldiston 2012; Ragusa 2010; Dowling 2004).

However, it would be a mistake to suggest that Simmel (1997[1903]) is entirely pessimistic about the cultural conditions of the modern city. The growth of a money economy and the expansiveness of population sizes means individuals are freed from a 'village' type of sociality where everyone knows everyone, and also personal business. The opportunity for one to be 'hidden' within the masses is more possible in an advanced metropolitan environment. However, it is in later essays, in particular his small examination of 'The adventure', that we can see optimism from Simmel. Here, specifically, he appears to perceive that within the very mundane flows of everyday life there are opportunities for escape (cf. Frisby 1992). On this issue he writes:

An adventure is certainly part of our existence, directly contiguous
with other parts which precede and follow it; at the same time, how-
ever, in its deeper meaning, it occurs outside the usual continuity
of this life. Nevertheless, it is distinct from all that is accidental and
alien, merely touching life's outer shell... Because of its place in our
psychic life, a remembered adventure tends to take on the qual-
ity of a dream... The more 'adventurous' an adventure, that is, the
more fully it realizes its idea, the more 'dreamlike' it becomes in our
memory. (Simmel 1997[1910], p. 222)

Adventure seeking is therefore a form of experiencing that can emerge in the everyday. For Simmel (1997[1910]) the content is meaningless to the analyst; rather it is the interpretation of events for the individual which deems it as an extraordinary adventure or not. Thus, adventuring can be as simple as taking alternative routes to work through to mutual gazing or flirting on the train.

In relation to a slow narrative, we can begin to see how the desire to engage in alternative spatial practices appears as a type of 'adventuring'. As a symbol of homogeneity and mundane sociality, the city and the everyday work that occurs within it are transcended momentarily through various behaviours. Cycling, for instance (see Ryle and Soper, this volume), enables the individual to experience enjoyable sensations, 
such as the wind blowing on one's face, that are largely 'denied' in the usual experiences of vehicular and public transport (cf. Soper 2007). Going to food markets allows the consumer to embrace and experience local cuisine and culture, which binds the individual's sense of identity to a 'sense of place' (Parkins and Craig 2006). Even the ability to meet with friends to have lunch in a park, where sociality and meaningful conversation (which Simmel also felt escaped the rational cage of modernity) are enjoyed, could be considered as an alternative practice to the everyday.

These notions are reminiscent, certainly, of the 'alternative hedonism' theories produced by Kate Soper (2007). She argues that through consumption practices, including that of consuming space, individuals' own pursuit of hedonistic pleasure, combined with a wider concern for issues like pollution and environmental degradation, can result in a broad uptake of activities that are conducive to a sustainable future. She writes:

Under this impulse, the individual acts with an eye to the collective impact of aggregated individual acts of affluent consumption for consumers themselves, and takes measures to avoid contributing to it. It is, for example, a decision to cycle or walk whenever possible in order not to add to the pollution, noise and congestion of car use. The hedonist aspect, however, of this shift in consumption practice does not reside exclusively in the desire to avoid or limit the unpleasurable by-products of collective affluence, but also in the sensual pleasures of consuming differently (Levett 2003, pp. 60-61). There are intrinsic pleasures to be had in walking or cycling which the car driver will not be experiencing.

(Soper 2008, p. 572)

She suggests (2008, p. 572), though, that these 'alternative' means of consumption must at times be encouraged though local/state 'policies' that actively aim to reduce car traffic and enhance the bicycle and walking experience. Planning initiatives of this type recur across metropolitan environments in which more traditional forms of transport, such as walking and bike riding, are encouraged and spaces for them constructed. My point of matching Soper's $(2007,2008)$ work to Simmel's here, however, is concerned less with the political and more with a cultural condition in the city which creates a desire for extraordinary sensations. Adventuring, whether it be through modes of transport or farmer's markets on a Saturday morning, taps into a 
collective disaffection with the offering of sensual pleasures found in the everyday, fast, homogenous and habitual consumer capitalist life.

Not all spaces in the city, however, are meaningless. There are areas which can encourage a 'slow' mindset, if we consider slowness to mean 'mindfulness', 'care' and 'attention' (see introductory chapter). It is important to reflect on these in order to locate the city symbolically as not simply another 'cathedral of consumption' (Ritzer 2010) but also a place with culturally meaningful spaces. These can include sites that encourage reflection on 'charismatic' pasts. Terlouw (2011, p. 339), for instance, suggests that

The here and now of everyday life is the domain of established regimes. To legitimize their ordinary rule, established regimes try to link up with distant charisma. This is one of the ways in which both traditional and bureaucratic regimes seek support from their population. They can legitimize their rule by linking their national narrative with the charisma embodied in special iconic places. Space is frequently used to construct linkages with the pure charisma of other times.

Monuments to past charismatic authority including monarchs and religious leaders reinforce for Terlouw (2011, p. 341) the legitimacy of present regimes. These include legitimating bureaucratic structures that have overcome old traditional forms of charismatic authority. The charismatic space in this case serves to identify that the present 'regime will perform even better' than its predecessors (Terlouw 2011, p. 341). How this relates to slowness, however, is less clear. I propose, though, that in certain spaces within the city the individual is called to reflect and meditate on symbols rather than just walk effortlessly past them without any reflexive prowess.

In neo-Durkheimian language, these sorts of area are those that not only allow people to reflect upon past traditions and perhaps feel some 'collective nostalgia' (Davis 1979) for times forgotten, but also enforce change on the body which results in shifts in micro-behaviour because of the force of broader cultural narratives. Described as 'sacred places', Phil Smith (1999, p. 19) suggests that

nearing the sacred place a penumbra of solemnity imposes itself on human behaviour, inviting, for example, the hushed tones, the straightened back, silent footsteps, slow breathing which in turn invoke physiological changes and direct memory towards the sacred and away from the mundane, liminal and profane. 
From war memorials to churches and through to sites of national significance (e.g. the Bastille or the World Trade Centre Memorial), these sites carry a cultural force which imposes itself upon the individual, but not as a form of discipline (cf. Foucault 1991[1975]). Rather, as Durkheim (1995[1912]) derived from his study of religion, they draw people in through collective values and mythologies or cultural narratives, and encourage contemplation, meaning and, potentially, slowness.

In relation to the slow paradigm, these sorts of space which are not hidden within the city can induce feelings of collective effervescence but mainly invoke a feeling of the sacred within the individual. This contrasts the proposal that the city is embedded in speed, consumerism and meaninglessness. From this perspective, cities are not simply monolithic consumer capitalist spaces that rely on re-enchantment through spectacle and/or simulations (Ritzer 2010; Baudrillard 1994); rather, cities are replete with those forms of place which create opportunities for engagement with sacred things that can enhance an 'authentic self'. Unlike a 'cosmopolitan' identity which can result in 'cosmopolitan' individuals (Parkins and Craig 2006, p. 4), the city with its various sacred places has for some time owned the cultural artifacts that encourage 'care, attention and mindfulness', which are central to the slow culture.

\section{Escaping the city}

The metropolis therefore cannot be seen as merely devoid of distinctiveness and cultural importance. However, these ideas are slightly discordant with the understanding of 'slowness' that is developed by Parkins and Craig (2006). Rather than seeing slowness in those social movements that embrace the logic of Carlo Petrini's 'slow food', slow culture has developed into a narrative that motivates a number of 'alternative' approaches to the everyday. The negotiation of space or the consumption of spaces that enhance the authentic self are examples of this.

However, for a growing set of disgruntled and disaffected individuals living within the confines of suburbia or the urban, city life imposes a level of stress and unhappiness that creates a desire to escape. It is clear that the city and its associated infrastructure and day-to-day activities, promotes habitual and ordinary behaviour. Most important, as Simmel (1997[1910]) shows in his essay on the adventure, are the interlocking moments of life that are accentuated by work. The city is for many people a place for work rather than play, and for a growing set of disgruntled individuals it is now becoming the profane. For instance, one participant in a study conducted in 2006 complains that 
I was sick of the city, and it was dirty and people are sort of always angry and stuff like that...yeah, and it was a stressful place and I wanted somewhere that was more peaceful

(Osbaldiston 2006, pp. 49-50)

Another participant in the same study says that they

got sick of the traffic. I got sick of the fake lifestyle really, you know no community mindedness everybody is so solitary... encapsulated in their own sort of space and just seem to be about achieving money and not caring about the planet.

(Osbaldiston 2006, p. 50)

For these individuals and thousands like them, the city has a profound influence on their daily lives, in a somewhat degrading manner. Stress, pollution, anger, traffic, congestion, overcrowding and speed are all problems of which these individuals finally get tired (see Osbaldiston 2006, 2012; Ragusa 2010, this volume; Dowling 2004).

Unlike sacred places, which invoke micro-bodily changes through meaningful and deeply subjective narratives and themes, the city leaves such a negative impression on these people that it becomes the 'profane place' (Smith 1999). For neo-Durkheimian Smith (1999, p. 19), this type of 'place' has an influence on the individual as profound as the sacred:

These narratives see human actions as polluting to the moral fabric of society and degrading to human spiritual values. Like sacred places, those which are profane are often founded upon narratives of violence... Profane places are more often, but not always - the locus of subsequent, equally ritualistic (to the sacred) attempts at destruction and obliteration... marked out by taboos and what Durkheim called 'rituals of avoidance'.

(Smith 1999, p. 19)

Within the city, there are several instances of once perceived profane places receiving significant rejuvenation to create new, sometimes chic, housing and other development. Inner-city suburbia and old factory districts are often turned into boutique-style living, attracting those from within the middle classes who seek a new 'style' of alternative living. Acknowledging this, we can also begin to question who defines the authentic here and who decides when the profane requires 'bulldozing', as Zukin (2008) reminds us. 
For a growing group of individuals, however, the city has become a symbol of the profane. Not only are the objective surrounds considered an impediment to self-actualisation (Simmel (1997[1903]) but the speed of the city and the velocity of contemporary life creates a need to 'slow' down and find more balance to living. This realisation encourages the individual to seek out alternative lifestyles, usually found outside the city and suburbs, called Lifestyle Migration, Amenity Migration or Seachange. These disgruntled urbanites seek a life more conducive to a sense of well-being and self-actualisation which they believe can be found in the rural or coastal lifestyles. Towns selected by these urban refugees are often underpinned by broad and romantic narratives which suggest that the place is the answer to life's ills. In particular, there are three major facets of regional living which attract the lifestyle migrant: the natural world, a nostalgia for the past and the notion of community (see Osbaldiston 2011, 2012; Moss 2006). In each instance the binary interplay between the country and the perceived profane qualities of the city is stark. The country is conceived of as clean, pure, untouched, sociable, warm, friendly, creative and, most importantly, slow. Areas like Canmore in Alberta, Canada, the Town of Golden in British Columbia, Jackson Hole in Wyoming, Tasmania in Australia, parts of rural France and the English countryside have all in recent years encountered unprecedented population growth, to which these slow seekers contribute significantly (Mitchell 2005; Osbaldiston 2012; Ragusa 2010; Burnley and Murphy 2004; Benson 2011). Importantly, like the sacred places above, these areas are perceived to offer sensations that are lacking in the metropolis and a natural environment that promotes slower, more meaningful lifestyles. The 'distinctiveness' of the landscape is also often considered as iconic to a national identity. For instance, Robinson and Stark (2006, p. 120) illustrate that Canadians, in particular Albertans, often describe their state through imagery of 'rolling foothills, forests without end and glacier-capped mountain playgrounds'. In Australia, iconic beaches and dusty outback landscapes sit deep in the collective imagination of Australiana, revealed specifically in film and literature (see Booth 2001; Drewe 1993). Classics such as Lawson's The Drover's Wife or Patterson's The Man from Snowy River serve to sacralise a particular type of landscape into the collective narrative of Australia. For those seeking refuge from the city, it is these types of narrative, alongside the general appeal of slower living, which reconnect the individual to a collective identity, promoting self-authenticity and, potentially, distinction (see below). 
It may be said, however, that this particular adoption of 'slowness' is not particularly new. The city has, since the development of industrial modernity, been construed in some circles as 'profane'-like, while the countryside lifestyle was seen to be unpolluted. Macnaughten and Urry (1998, p. 175) reveal, for instance, that in industrialised England

the countryside came increasingly to be desired because of its visual qualities mediated through the representation of space via the notion of landscape... the industrial town was seen as thoroughly polluted, as unnaturally invading all the human orifices.

Country life was lauded as 'significant' and a symbol of true 'Englishness' (Macnaughten and Urry 1998, p. 180). Their landscapes were 'unspoiled' by modernisation and a proper mode of engagement which involved thoughtful, quiet and unobtrusive practices was established. In places like the Lake District, these practices, which involve quiet walking, yachting and various other forms of 'romantic' negotiation of the landscape, are still in fashion today (Macnaughten and Urry 1998, p. 187). However, escaping the city was seen as more than just an escape from a horribly polluted city environment; it also became a sign of good taste for the bourgeois and a symbol of proper living. This reality raises new questions of motivation among today's lifestyle migrants (see discussion below). In particular, who defines what is authentic and the impact that this has on local dynamics and cultural form are important considerations.

However, this aside, there are other historical examples of those who sought out the simplicity of the good life in the country prior to the emergence of the lifestyle migration phenomenon. For instance, Thoreau's (2008[1854]) sojourn to Walden reflects a similar ideal to today's amenity-led migrants. He writes:

I went to the woods because I wished to live deliberately, to front only the essential facts of life, and see if I could not learn what it had to teach, and not, when I came to die, discover that I had not lived... I wanted to live deep and suck out all the marrow of life, to live so sturdily and Spartan-like as to put to rout all that was not life, to cut a broad swath and shave close, to drive life into a corner, and reduce it to its lowest terms.

(Thoreau 2008[1854], p. 45)

The logic of Thoreau's thoughts here is that within the city, the ability to achieve what he desired most of all, which we could surmise was 
a type of self-authenticity, was impossible. The country, on the other hand, and it's simple and slow tempo encourage feelings of solitude, peace and contemplativeness. The disjuncture between the city and the country here is reminiscent of Raymond Williams' (1973) famous claim that the two places are embedded in a slow/fast rhetoric. Those living in the country were considered old-fashioned or 'traditional', whereas the city was conceived of as progressive and advanced (Williams 1973). From a broad perspective, this is essentially what Lifestyle Migration is founded on (see e.g. Benson 2011). This view designates the country lifestyle as simple and community focused - a step back in time. Most importantly, however, it is symbolically distant from a city that is forever advancing, progressing and accelerating, but which also inhibits the self in its development. In short, the contemporary escape from the city can be seen as a manifestation of a long historical binary opposition between the sacred countryside and the profane and unnatural cityscape.

Lifestyle Migration from this angle can again be seen as an 'alternative' method of consuming places slowly. In this instance, it is a more drastic measure wherein the individual employs a significant ritualistic avoidance strategy and immerses themselves into a culture and landscape which are far removed from the city. Once the individual is immersed into a space that is surrounded by a pristine natural world and a small-town country atmosphere, the opportunities to 'slow down' are abundant. As Smith (1999) considers in the 'sacred place', these new surroundings promote a change in behaviour and subsequently in identity. This is precisely what they seek through their urban escape. It is via their new location that lifestyle migrants find a 'congruence' between their own values and beliefs, thus providing a feeling of affirmation and authenticity (Vannini and Burgess 2009, p. 104). Like 'alternative hedonism', however, there are critical questions about who can actually engage with this slow form of living. The premise, though, is that by consuming different or alternative places that are considered more authentic, individuals can find more meaning in their life and can find slow havens. This conceptual framework is found not only within this dramatic movement but also within other manifestations of slowness (including Slow Food; see Lindholm and Lie, this volume).

\section{Discovering new places slowly}

Another growing social trend is the adoption of a form of tourism under the banner of the slow. Called simply 'Slow Travel' or 'Slow Tourism', this apparently new modality of travel seeks to overcome the rushed 
nature of the postmodern tourist by allowing them to become immersed in the local culture, cuisine and landscapes. Unlike Urry's (2002, p. 92) 'three-minute' tourist, those engaging in slow travel experiences spend lengthy amounts of time in accommodation that is often self-catering (Footprint Choices 2012). This means essentially that the traveller is not just 'staying' at their destination but 'living' there (Footprint Choices 2012, para.5). This includes being able to enter into local settings and immersing oneself in the cultural life that is found within it. Such a view also encourages a flaneuristic type of engagement with place where the individual becomes part of the social life though their wanderings and slow engagement with the social. Rather than speeding in hire cars to 'must-see' destinations and other speedier modes of transportation, the slow traveller experiences sensations that other tourists miss in their harried and often stressful journeyings. Speakman (2005, cited in Lumsdon and McGrath 2011, p. 269) discusses this point further:

Contrary to the seductive automobile advertisements, quality of experience is not about speed. The real pleasure of travelling on barge or cruise boat along a waterway lies in travelling at a gentle pace through a slowly changing landscape. Walking and cycling are forms of tourism transport that offer so much more than the car in terms of perceiving the environment in far greater detail, and allowing other senses to share in that perception - experience the sounds, the touch, even the taste and the smell of the natural world and cultural landscape. In transport for tourism terms, therefore slow is beautiful.

Once again the emphasis in this statement is on the alternative sensations that one can experience through a slow form of experiencing place. Thus tourism is less about the 'gaze' that Urry (2002) famously argued for and more about the holistic experience of a new place, a new culture and subsequently a distinction from fake tourism.

Conceptualising this evolving form of tourism has been limited in the academic sphere. One of the few illustrations can be found in Lumsdon and McGrath's (2011, p. 276, italics added) work, which suggests that slow travel can be thought of in the following way:

Slow travel is a sociocultural phenomenon, focusing on holidaymaking but also on day leisure visits, where use of personal time is appreciated differently. Slowness is valued, and the journey is integral 
to the whole experience. The mode of transport and the activities undertaken at a destination enhance the richness of the experience through slowness. Whilst the journey is the thing and can be the destination in its own right, the experience of locality counts for much, as does reduced duration or distance of travel.

The emphasis here is again on the individual consuming differently for their own sensual delight. However, websites dedicated to advocating slow tourism are keen to identify other ethical reasons for enjoying an alternative approach to travel. This includes 'voluntourism', where people can utilise their skills and resources to assist less advantaged communities through welfare groups and non-government agencies (Footprint Choices 2011). Voluntourism (voluntourism.org 2012), a website designed to assist those considering the option, portrays the opportunity to combine volunteer work with the tourist experience as allowing the individual to interact with a destination in ways that exceed 'expectation'.

Like 'alternative hedonism' or 'slow food', the political potential of slow tourism is described by Lumsdon and McGrath (2011, p. 277) as a way for tourism to be 'reconfigured to offer an enhanced experience and reduced environmental impact'. In another exploration of the topic, Dickinson, Lumsdon and Robbins (2010, p. 295) suggest that in the future, in the case of a 'low-carbon' transition, the ability of slow tourism to become a tool for a more sustainable outcome should be taken seriously. Certainly, in an age when climate change mitigation and the debates within it weigh heavily on fossil-fuel-dependent industries, this suggestion has merit. Like the consumption of alternative food practices that identify with concerns for sustainability (Parkins and Craig 2006), or even of other products, such as fashion (see Schor, this volume), which recognises the finitude of resources, slow travel can adopt those narratives that seek to lessen the footprint of travel upon the world.

However, conceptualising slow travel further for the purposes of this chapter need not go too far beyond the Durkheimian language presented by Smith (1999) and others. Simply put, slow travel engages a narrative that views the tourist experience as 'sacred'. This subject the sacred - has been the focus of important pieces of research on previous tourism (Cohen 1979; MacCannell 1973; Rojek 1993). However, rather than treating the experience as a pilgrimage similar to the rituals found in Durkheim's Elementary Forms of Religious Life, I wish to suggest that the tourist experience through the 'mindfulness' of slow 
travel encourages a rendering of these 'new' places as sacred. As Smith (1999) locates in his typology of sacred places, these new locales are treated with high esteem and, like the sacred places found in the city, encourage a different perception and behaviour that is distinct from the profane city/urban life. Thus, unlike a narrative that suggests that tourism is simply for rest and recovery from a stressful and alienating world (Cohen 1979), slow tourism embraces a paradigm that suggests that this consuming place enables a sense of self-authenticity or selfactualisation. It is only through experiencing place slowly that this is made possible, however. Again, unlike Urry's (2002) conceptualisation of the tourist who consumes predominantly with their eyes, the slow tourist seeks to discover newness by embracing all of the sensations that are on offer. By engaging fully with the local culture, space, natural wonder and everyday life, the individual immerses themselves into new and distinct tastes, smells, sounds and sights. Admittedly this is only a brief theoretical discussion of what is a burgeoning social practice. More thought will need to be applied in the future to how we might conceptualise it not only within the broader slow cultural narrative but also within the expansive and well-founded tourism literature.

\section{Whose authenticity is it anyway?}

The thread tying what is essentially a messy reading of slowness and place in this chapter is the notion of authenticity or, rather, selfauthenticity, which has re-emerged in importance during the past few years (Lindholm 2008; Lindolm and Zúquete 2010; Vannini and Burgess 2009). The argument which has been implicit throughout has been that authenticity is a driving force behind the re-negotiation of spatial practices through slowness. Embedded in the theory that the slow is equated with other narratives, such as 'care', 'mindfulness' and 'contemplation', is a desire for self-authenticity by engaging with authentic objects and surrounds. Such notions are built upon Simmel's own principles for cultivation that are found in his theories of culture (cf. Nedelmann 1991). Here, objective culture is subjectified for the development of the self or, in the case of this chapter, the actualisation of the 'authentic' or genuine self. However, as Simmel (1997[1912], p. 73) recounts in his essay 'The tragedy of culture', this process has been significantly disturbed through modernisation. He writes:

There thus emerges the typical problematic condition of modern humanity: the feeling of being surrounded by an immense number of 
cultural elements, which are not meaningless, but not profoundly meaningful to the individual either; elements which have a certain crushing quality as a mass because an individual cannot inwardly assimilate every individual thing, but cannot simply reject it either, since it belongs potentially, as it were, to the sphere of his or her cultural development.

As suggested earlier in the discussion on the city, objective culture has outgrown the capacity for the self to subjectify it for self-development. Perception becomes deadened and cultural life blasé. Of course, such metaphysical commentary derived from Kantian discourse should be treated with some scepticism. Elsewhere in relation to Lifestyle Migration or Seachange, I have argued that these theoretical notions should not be considered as 'real' but in fact as 'social constructs' which appear to guide behaviour today (Osbaldiston 2012). In other words, individuals recognise that in order to self-actualise, they need to embrace an alternative mode of living that engages with slower or more even modes of objective culture. Negotiating space and place under the paradigm of the slow is to do so with an eye towards experiencing something which enchants the senses rather than deadens them.

However, in analysing cultural life, we cannot be naïve to the problems of authenticity. In particular, the ability for the narrative of authenticity to distinguish, separate or gentrify is a side effect of the slow phenomenon that needs to be considered (Benson and O'Reilly 2009; Zukin 2008). For instance, in response to Soper's (2008) proposition for more investment in 'alternative hedonism', both theoretically and politically, urban sociologist Sharon Zukin (2008, p. 728) reflects that 'we can only see spaces as authentic from outside them'. In her assessment of Soho, for instance, this critical perspective takes on more empirical shape:

When consumption spaces manipulate authenticity for new residents' needs, they enable them - not so innocently - to stake their own claim to the neighborhood. But as SoHo shows, alternative consumption sites legitimise the area as a commercial attraction. The neighborhood becomes a target of wealthy consumers, chain stores, and real estate developers - an emporium for tourists and shoppers. When commercial rents rise above what experimental outposts of difference can afford to pay, they shut down or migrate to less expensive areas. (Unlike some small, specialised retail stores, they depend on face-to-face experience, so they cannot just move their business to the Internet.) Artists and hipsters are well aware of the significant role 
their tastes play in this process. But it is not the presence of artists that sets the process of displacement in motion: it is the presence of their taste for authenticity in the product mix, store design, and intangible ambiance of restaurants, boutiques, and gourmet stores.

From here we can question the notion of authenticity which is derived from outside (see above) and then imposed upon spaces by outsiders. Zukin (2008, p. 745) concludes by arguing that despite the work of authenticity which occurs in places that are selected for rejuvenation (or gentrification) by the middle or creative classes, such as Soho, 'the norm of alternative consumption becomes a means of excluding others from their space'. This includes racial as well as social class distinction.

This notion of how taste operates as a mode of class distinction is developed in relation to lifestyle migration in the work of Benson (2011; see also Benson 2009, forthcoming) on British residents in rural France. Their imaginings of the area, which drive the decision to migrate and also their expectations and experiences of life at their destination, are encapsulated within the notion of the rural idyll, a cultural construction of rurality through which the French countryside is appropriated. As Benson argues, the migration to this rural destination can be read, in Bourdieusian terms, as a 'desire for difference' (2009); driven by the pursuit of distinction, it makes apparent the intra-class processes that go on within the British middle classes.

Authenticity is central to these processes of distinction. The image of the rural idyll mobilised by Benson's respondents focuses on the authentic life that is uniquely available at their destination which through migration they desire to become part of. Their practices and actions reveal the self-conscious performance of this better way of life, as they seek authentication from their middle-class peers. Increasingly, notions of what constitutes authentic living in rural France become increasingly individualised and nuanced. While the general tropes of rurality remain central, individual migrants present their own understandings of how this authentic life can and should be led. The pursuit of a better way of life that lay at the core of their migration is a persistent feature of their post-migration lives, as the genteel struggles over their class position continue (Benson 2011, forthcoming).

\section{Conclusion}

This chapter has sought to explore the notion of slowness within space/place. Unlike the work of Parkins and Craig (2006), it has to 
avoid discussing the culture of the slow through only explicitly named 'slow' movements. Rather, as discussed earlier, there are several key sites where alternative modes of consuming space fall under the umbrella of what is a loose definition of what constitutes the 'slow' (see Introduction). Indeed, in the everyday, as Soper (2008) has shown, there are many instances where the same principles of care and mindfulness that attend to movements like slow food are embraced by individuals seeking escape from the everyday or the rationalised world. In particular, the city not only causes some to seek ritualistic escape through Lifestyle Migration but also encourages alternative modes of experiencing space. Whether it is through bicycle riding, walking, taking ferries or simply through enjoyment of friends during lunch breaks in the park, there is a sense that the everyday can be transcended through spatial practice - a moment of adventuring in an otherwise seamless day (Simmel 1997[1910]).

In the latter half of the chapter, the notion of sacrality was introduced to the debate through Smith (1999). Here, using Lifestyle Migration and Slow Tourism as examples, it was argued that under the paradigm of authenticity, individuals seek out sites for their own personal actualisation which can be considered as the 'sacred experience'. However, as the chapter concludes, the notion of authenticity can be contested critically. Benson's (2011) work alongside other thinkers, especially Zukin (2008, 2010), opens up space for this critique. Who decides what is authentic? Who decides what is sacred? How does this decision impose itself upon local spaces and cultural conditions? What impact does this have on equity? Who is excluded? Such questions need not remain the focus of spatial analysis. For instance, in the discussion of Slow Food, the critical argument of who is invited to the table and who is excluded is worth debating. In particular, cuisine that is at times quite expensive ultimately denies entry to the lower classes. Further, it is evident that authenticity is a contested issue, and who decides what is authentic is open (see Lindholm and Lie, this volume). There is no room to expound upon this idea here, though.

For the middle classes, however, the quest for the authentic remains a real pursuit. The side effects are something to debate among analysts of space and culture. While slowness has emerged as a political narrative worthy of consideration for a sustainable future, this chapter shows that there is a powerful cultural theme which needs to be acknowledged. Not all consumers of slowness do so with a broader ecological focus alongside their own personal desires. Lifestyle migrants, slow travellers, bicycle riders, walkers and other proponents of spatial consumption can 
at times be centred solely on individual 'hedonist' desires for alternatives to the mundane. Simmel (1997[1910]) shows us that this is not new. Rather, we have been seeking enchantment for a disenchanted world since modernity. Slowness potentially emerges as another manifestation of this. However, as quoted earlier, Simmel's (1997[1895]) powerful critique that capitalism subsumes ideas as well as objects gives us caution to be too optimistic on this latest counter to rapid modernisation.

\section{Acknowledgement}

I would like to acknowledge the assistance of Dr Michaela Benson of York University for her assistance in the compiling of thoughts and ideas for this chapter.

\section{References}

Adam, B., 1990, Time and Social Theory, Temple University Press, Philadelphia.

— 1995, Timewatch: The Social Analysis of Time, Polity Press, Cambridge.

- 1 1998, Timescapes of Modernity: The Environment and Invisible Hazards, Routledge, New York.

Baudrillard, J., 1994, Simulacra and Simulation, S. F. Glaser (trans.), University of Michigan Press, Michigan.

Beck, U., 1992, Risk Society: Towards a New Modernity, M. Ritter (trans.), SAGE, London.

2006, The Cosmopolitan Vision, C. Cronin (trans.), Polity Press, Cambridge. Benson, M., 2009, 'A desire for difference: British lifestyle migration to southwest France', in M. C. Benson and K. O'Reilly (eds.), Lifestyle Migration: Expectations, Aspirations and Experiences, Ashgate, Farnham, pp. 121-136.

Benson, M., 2011, The British in Rural France: Lifestyle Migration and the Ongoing Quest for a Better Way of Life, Manchester University Press, Manchester.

Benson, M., forthcoming, 'Living the 'Real' dream in La France Profonde: Lifestyle migrants and the ongoing quest for the authentic', Anthropological Quarterly.

Benson, M. and O'Reilly, K., 2009, Lifestyle Migration and the Ongoing Quest for a Better Way of Life, Manchester University Press, Manchester.

Booth, D., 2001, Australian Beach Cultures: The History of Sun, Sand and Surf, Frank Cass \& Co, London.

Burnley, I. and Murphy, P., 2004, Sea Change: Movement from Metropolitan to Arcadian Australia, UNSW Press, Sydney.

Cohen, E. H., 1979, 'A phenomenology of tourist experiences', Sociology, 13, 179-201.

Craik, J., 1997, 'The culture of tourism', in C. Rojek and J. Urry (eds.), Touring Cultures: Transformations of Travel and Theory, Routledge, London, pp. 113-136. Davis, F., 1979, Yearning for Yesterday: A Sociology of Nostalgia, Free Press, New York. 
Dickinson, J. E., Lumsdon, L. and Robbins, D. K., 2010, 'Slow travel: Issues for tourism and climate change', Journal of Sustainable Tourism, 19(3), 281-300.

Dowling, C., 2004, Seachange: Australians in Pursuit of the Good Life, Exisle, Sydney. Drewe, R., 1993, The Penguin Book of the Beach, Penguin Books, Melbourne.

Durkheim, E., 1995[1912], Elementary Forms of Religious Life, K. E. Fields (trans.), The Free Press, New York.

Footprint Choices, 2012, 'What is slow travel?', Slow Movement, viewed 23 February 2012, http://www.slowmovement.com/slow_travel.php.

Foucault, M., 1991[1975], Discipline and Punish, A. Sheridan (trans.), Penguin Books, London.

Frisby, D., 1992, Simmel and Since: Essays on Georg Simmel's Social Theory, Routledge, London.

Hochschild, A., 1997, The Time Bind: When Work Becomes Home and Home Becomes Work, Metropolitan Books, New York.

Hoey, B., 2010, 'Personhood in place: Personal and local character for sustainable narrative of self', City and Society, 22(2), 237-261.

Kendall, G., Skrbis, Z. and Woodward, I., 2008, The Sociology of Cosmopolitanism, Palgrave Macmillan, Bassingstoke.

Lamanna, M., 2004, 'Decentering Durkheim: his writings on the family', in Proceedings of the American Sociological Association Conference 2004, San Francisco, viewed 14 August 2009, http://www.allacademic.com/meta/p108541_index. html.

Lasch, C., 1979, Haven in a Heartless World: The Family Besieged, Basic Books, New York.

Lindholm, C., 2008, Culture and Authenticity, Blackwell, Malden.

Lindholm, C. and Zúquete, J. P., 2010, The Struggle for the World: Liberation Movements for the 21st Century, Stanford University Press, Stanford.

Lumsdon, L. M. and McGrath, P., 2011, 'Developing a conceptual framework for slow travel: a grounded theory approach', Journal of Sustainable Tourism, 19(3), 265-279.

MacCannell, D., 1973, 'Staged authenticity: arrangements of social space in tourist settings', American Journal of Sociology, 79, 589-603.

Macnaughten, P. and Urry, J., 1998, Contested Natures, Sage, London.

Miele, M., 2008, 'Cittaslow: producing slowness against the fast life', Space and Polity, 12(1), 135-156.

Mitchell, C. J. A., 2005, 'Population growth and external commuting to Canada's rural and small town municipalities', Canadian Journal of Regional Science, 20, $15-34$.

Moss, L. A. G. (ed.), 2006, The Amenity Migrants: Seeking and Sustaining Mountains and Their Cultures, CABI, Oxfordshire.

Murdoch, J. and Day, G., 1998, 'Middle class mobility, rural communities and the politics of exclusion', in P. Boyle and L. Halfacree (eds.), Migration into Rural Areas, Wiley, Chichester, pp. 186-199.

Nedelmann, B., 1991, 'Individualisation, exaggeration and paralysation: Simmel's three problems of culture', Theory, Culture and Society, 8(3), 169-193.

Osbaldiston, N., 2006, Risk and Seachange: Discourses of Risk-Taking and Individualisation within a Contemporary Australian Phenomenon, BSocSci (Hons) thesis, Queensland University of Technology, Brisbane. 
2011, 'The authentic place in amenity migration discourse', Space and Culture, 14(2), 214-226.

—, 2012, Seeking for Authenticity in Place, Culture and the Self: The Great Urban Escape, Palgrave MacMillan, New York.

Pahl, R., 2005, Are all communities communities in the mind?', Sociological Review Monograph, 53, 621-640.

Parkins, W. and Craig, G., 2006, Slow Living, Berg, Oxford.

Pink, S., 2007, 'Sensing cittaslow: slow living and the constitution of the sensory city', Sense and Society, 2(1), 59-77.

Ragusa, A., 2010, 'Seeking trees or escaping traffic: socio-cultural factors and 'treechange' migration in Australia', in G. W. Luck, R. Black and D. Race (eds.), Demographic Change in Rural Landscapes: What Does It Mean for Society and the Environment?, Springer, London, pp. 71-99.

Relph, E. C., 1976, Place and Placelessness, Pion, London.

Ritzer, G. 2010. Enchanting a Disenchanted World: Continuity and Change in the Cathedrals of Consumption, Sage, Thousand Oaks, California.

Robinson, B. and Stark, C., 2006, 'Alberta's amenity rush', in L. A. G. Moss (ed.), The Amenity Migrants: Seeking and Sustaining Mountains and Their Cultures, CABI, Oxfordshire, pp. 120-134.

Rojek, C., 1993, Ways of Escape: Modern Transformations in Leisure and Travel, Palgrave Macmillan, Bassingstoke.

Shields, R., 1992, Places on the Margin: Alternative Geographies of Modernity, Routledge, London.

Simmel, G., 1997[1895], 'The alpine journey', S. Whimster (trans.), in D. Frisby and M. Featherstone (eds.), Simmel on Culture: Selected Writings, Sage, London, $174-186$.

, 1997[1903], 'The metropolis and Mental Life', M. Ritter (trans.), in D. Frisby and M. Featherstone (eds.), Simmel on Culture, Sage, London, pp. 174-186.

- 1997[1910], 'The adventure', K. Wolff (trans.), in D. Frisby and M. Featherstone (eds.), Simmel on Culture: Selected Writings, Sage, London, pp. 221-232.

-1997[1912], 'The concept and tragedy of culture', M. Ritter and D. Frisby (trans.), in D. Frisby and M. Featherstone (eds.) Simmel on Culture: Selected Writings, Sage, London, pp. 120-130

Smith, P., 1999, 'The elementary forms of place and their transformations: a Durkheimian model', Qualitative Sociology, 22(1), 13-36.

Soper, K., 2007, 'Rethinking the 'good life': the citizenship dimension of consumer disaffection with consumerism', Journal of Consumer Culture, 7(2), $205-229$.

— 2008, 'Alternative hedonism, cultural theory and the role of aesthetic revisioning', Cultural Studies, 22(5), 567-587.

Terlouw, K., 2011, 'Charisma and space', Studies in Ethnicity and Nationalism, 10(3), 335-348.

Thoreau, H. D., 2008[1854], Walden and on the Duty of Civil Disobedience, viewed 15 January 2009, http://www.gutenberg.org/etext/205.

Urry, J., 2002, The Tourist Gaze (2nd edn), Sage, London.

—, 2011, The Tourist Gaze 3.0, Sage, Los Angeles. 
Vannini, P. and Burgess, S., 2009, 'Authenticity as motivation and aesthetic experience', in P. Vannini and J. P. Williams (eds.), Authenticity in Culture, Self and Society, Ashgate Publishing, Burlington, pp. 103-120.

Voluntourism, 2012, 'Welcome potential VolunTourists', viewed 23 February 2012, http://www.voluntourism.org/travelers.htm.

Williams, R., 1973, The Country and the City, Chatto and Windus, London.

Woodward, I., 2007, Understanding Material Culture, Sage, London.

Zukin, S., 2008, 'Consuming authenticity', Cultural Studies, 22(5), 724-748. , 2010, Naked City: The Death and Life of Authentic Urban Places, Oxford University Press, Oxford. 